\title{
Determination of Trace Amounts of Copper in Samples of Sarcheshmeh Copper Mine Using Dispersive Liquid-Liquid Microextraction Based on the Solidification of Floating Organic Droplets Prior to FAAS
}

\author{
Farzaneh Arabpour ${ }^{1,}$, Sayed Zia Mohammadi ${ }^{2}$ \\ ${ }^{1}$ Sarcheshmeh Copper Mine, Kerman, Iran \\ ${ }^{2}$ Department of Chemistry, Payam Noor University, Tehran, Iran
}

Email address:

F_arabpoor231@yahoo.com (F. Arabpour)

*Corresponding author

\section{To cite this article:}

Farzaneh Arabpour, Sayed Zia Mohammadi. Determination of Trace Amounts of Copper in Samples of Sarcheshmeh Copper Mine Using Dispersive Liquid-Liquid Microextraction Based on the Solidification of Floating Organic Droplets Prior to FAAS. Science Journal of Analytical Chemistry. Vol. 5, No. 6, 2017, pp. 104-106. doi: 10.11648/j.sjac.20170506.15

Received: November 1, 2017; Accepted: November 20, 2017; Published: December 18, 2017

\begin{abstract}
In this article dispersive liquid-liquid microextraction $[1,2]$ based on the solidification of floating organic drop (DLLME-SFO) [3] was successfully used as a sample preparation method prior to flame atomic absorption determination of trace amount of copper in standard and wastewater samples [4]. Several factors that may be affected on the extraction process, such as extraction and disperser solvent, the volume of extraction and disperser solvent, effect of salt, $\mathrm{pH}$ of the aqueous solution and extraction, time and Ions effect were optimized [5]. Under the best experimental conditions, the calibration curve was linear in the range of $0.8 \mathrm{ng} \mathrm{mL}^{-1}-0.5 \mu \mathrm{g} \mathrm{mL}^{-1}$ of copper and detection limit was $0.2 \mathrm{ng} \mathrm{mL}^{-1}$ in the original solution (3Sb/m). The relative standard deviation seven replicate determination of $0.1 \mu \mathrm{g} \mathrm{mL}^{-1}$ copper was $\pm 1.9 \%$. The high efficiency of DLLME-SFO to carry out the determination of copper in complex matrices was demonstrated. Finally, the proposed method has been applied for determination of trace amount of copper in standard and wastewater samples of Sarcheshmeh Copper mine and other factory with satisfactory results.
\end{abstract}

Keywords: DLLME, Solidification, Wastewater

\section{Introduction}

Copper is found as a pure metal in nature, and this was the first source of the metal to be used by humans, ca. $8000 \mathrm{BC}$ $[6,7]$. It was the first metal to be smelted from its ore, ca. $5000 \mathrm{BC}$, the first metal to be cast into a shape in a mold, ca. $4000 \mathrm{BC}$ and the first metal to be purposefully alloyed with another metal. Copper is essential to all living organisms as a trace dietary mineral because it is a key constituent of the respiratory enzyme complex [8]. In molluses and crustacea copper is a constituent of the blood pigment hemocyanin, replaced by the iron-complexed hemoglobin in fish and other vertebrates [9]. In humans, copper is found mainly in the liver, muscle, and bone $[10,11]$. The adult body contains between 1.4 and $2.1 \mathrm{mg}$ of copper per kilogram of body weight. Hence a healthy human weighing 60 kilogram contains approximately $0.1 \mathrm{~g}$ of copper. However, this small amount is essential to the overall human well-being [12]. Copper compounds are also used as bacteriostatic agents, fungicides, and wood preservatives. A freshly exposed surface of pure copper has a reddish-orange color. [13] It is used as a conductor of heat and electricity, [14, 15] as a building material and as a constituent of various metal alloys, such as sterling silver used in jewelry, cupronickel used to make marine hardware and coins and constantan used in strain gauges and thermocouples for temperature measurement.

Numerous copper alloys have been formulated, many with important uses. Brass is an alloy of copper [16] and zinc. Bronze usually refers to copper-tin alloys, [17] but can refer 
to any alloy of copper such as aluminium bronze. Copper is one of the most important constituents of silver and carat gold and carat solders used in the jewelry industry, modifying the color, hardness and melting point of the resulting alloys. Some lead-free solders consist of tin alloyed with a small proportion of copper and other metals. [18]

\section{Instrumentation}

Varian model AA 220 flame atomic absorption spectrometer (Australia), a selenium hallow cathode lamp as radiation source (Hamamatsu Photonics, Japan) at $196.0 \mathrm{~nm}$ with a slit width of $0.7 \mathrm{~nm}, 23 \mathrm{~mA}$ current and deuterium background corrector, was used for measurement.

The $\mathrm{pH}$ values were measured with a Metrohm $\mathrm{pH}$-meter (model: 827, Swiss) supplied with a glass combined electrode. The Centurion Scientific centrifuge (model SIGMA3-16, Germany) was used for centrifuging.

\subsection{Reagents and Solutions}

All chemicals used in this work, were of analytical reagent grade and were used without further purification. Deionised water was used for all dilutions. Stock solutions of diverse elements were prepared from high purity compounds. The calibration standards were not submitted to the preconcentration procedure. All reagents were evaluated for their contribution to $\mathrm{Cu}$ contamination in the blanks. $\mathrm{HNO}_{3}$ (65\%), $\mathrm{HCl}(37 \%), \mathrm{H}_{3} \mathrm{HPO}_{4}$ and $\mathrm{NaH}_{2} \mathrm{PO}_{4} \cdot 2 \mathrm{H}_{2} \mathrm{O}$ (analytical grade) and $\mathrm{NaOH}$ solutions was used for adjust $\mathrm{pH}$. Phosphate buffer solutions $\left(\mathrm{H}_{2} \mathrm{PO}_{4}{ }^{-} / \mathrm{H}_{3} \mathrm{PO}_{4}\right)$ were prepared by mixing of appropriate volumes of $1 \mathrm{~mol} \mathrm{~L}^{-1}$ sodium dihydrogene phosphate and phosphoric acid solutions for $\mathrm{pH} 4$.

\subsection{General Procedure}

A solution contains $5.0 \mu \mathrm{g} \mathrm{L}^{-1} \mathrm{Cu}, \mathrm{NaCl} 10 \%$ and baffer was placed in a screw cap glass test tube with conical bottom. $1.5 \mathrm{~mL}$ of ethanol (disperser solvent) contains $25 \mu \mathrm{L}$ of $1-2$ dekanol (extraction solvent) was injected rapidly into a sample solution. A cloudy solution (resulted from dispersion of fine droplets of 1-2 dekanol in aqueous sample) was formed in the test tube. The mixture was then centrifuged for $5 \mathrm{~min}$ at $4000 \mathrm{rpm}$. The sediment phase was removed by using a $50 \mu \mathrm{L}$ micro syringe and $0.50 \mathrm{~mL}$ of ethanol was added to it. The final solution was aspirated directly into the flame of AAS against the blank.

\subsection{Result and Discussion}

In this study, a combination of DLLME with FAAS was developed for determination Copper. Several factors that may affect the preconcentration and extraction process, including $\mathrm{pH}$, type and volume of disperse and extraction solvent, salt type and volume, centrifuging time and rate and extraction time were optimized.

\subsubsection{Effect of $\mathrm{pH}$}

Since the $\mathrm{pH}$ of the aqueous sample solutions is an important analytical factor in DLLME. The influence of $\mathrm{pH}$ on the preconcentration of the analyte ions was examined in the $\mathrm{pH}$ range of 4-11 keeping the other parameters constant. The $\mathrm{pH}$ of the metal sample solutions was adjusted by using with $\mathrm{NaOH}$ and $\mathrm{HNO}_{3}$ solutions. The results are shown in Figure 1 and showed that maximum recovery for the analyte ions were obtained in the $\mathrm{pH}$ range of 4 . Accordingly, the further studies were down at $\mathrm{pH} 10$ by using $0.1 \mathrm{~mol} \mathrm{~L}^{-1}$ phosphate buffer solutions.

\subsubsection{Effect of Volume of Disperser and Extraction Solvent}

In order to test the effect of solvent volume on the recovery, different volumes of disperser solvent (0.5-3.0 mL ethanol) and different volumes of extraction solvent (15-75 $\mu \mathrm{L} 1-2$ dekanol) were studied. It was observed that quantitative recovery was obtained at $1.5 \mathrm{~mL}$ of ethanol and $25 \mu \mathrm{L}$ of $1-2$ dekanol. However, for convenience, all the experiments were performed with this result.

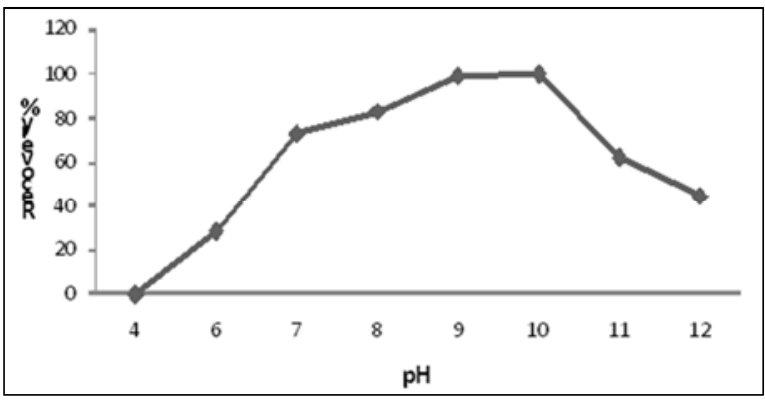

Figure 1. Effect the $\mathrm{pH}$ on the extraction of $\mathrm{Cu}$.

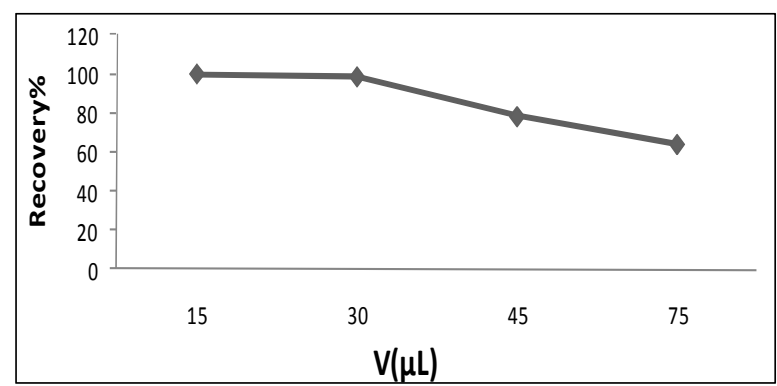

Figure 2. Effect the extraction solvent on the extraction of $\mathrm{Cu}$.

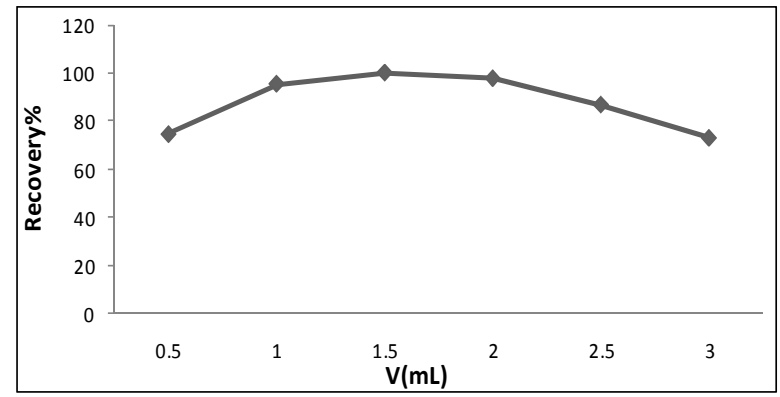

Figure 3. Effect the volume of disperser solvent.

\subsubsection{Effect of Salt}

The influence of ionic was eveluted at $10 \%(\mathrm{w} / \mathrm{v}) \mathrm{NaCl}$ levels while other parametrs were kept constant. It was observed that $1 \mathrm{ml}$ of $\mathrm{NaCl} 10 \%$ increase recovery and more 
than this volume decrease. Therefor $1 \mathrm{ml}$ was used in all experiments.

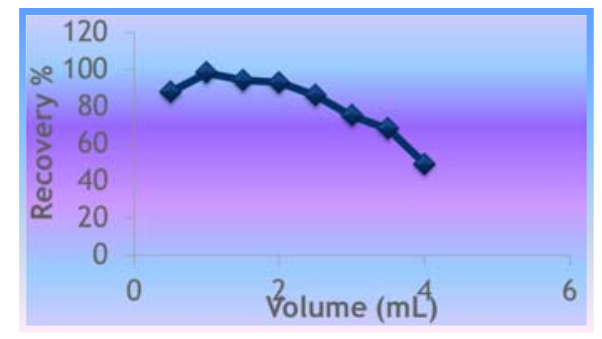

Figure 4. Effect the salt volume on the extraction of $\mathrm{Cu}$.

\subsubsection{Effect of the Extraction Time}

The extraction of $\mathrm{Cu}$ was also studied as a function of extraction time at the optimum conditions. Extraction time was measured by varying the equilibrium extraction time in the range of 1-7 min. The extraction efficiency of $\mathrm{Cu}$ showed that after $3 \mathrm{~min}$, maximum recovery was obtained. Therefore, extraction time 3 min was used in all subsequent experiments.

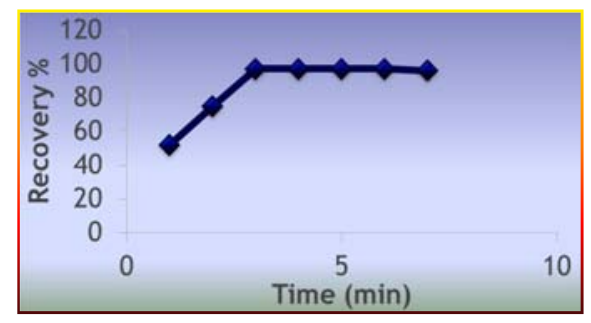

Figure 5. Effect of the extraction time on the extraction of $\mathrm{Cu}$.

\section{Analytical Figures of Merit}

Under the optimal conditions, the calibration curve for $\mathrm{Cu}$ were linear in the range of $0.50-0.80 \mu \mathrm{g} \mathrm{mL}^{-1}$ in the final solution. Detection limit based on eight times the standard deviation of the blank was $0.20 \mathrm{ng} \mathrm{mL}^{-1}$ in the final solution. seven replicate determination of $0.1 \mu \mathrm{g} \mathrm{mL}^{-1}$ of $\mathrm{Cu}$ give a relative standard deviation of $1.9 \%$ obtained.

\section{Application to Real Samples}

The high efficiency of proposed method to carry out the determination of Copper in complex matrices was demonstrated. The proposed method has been applied for determination of trace amount of $\mathrm{Cu}$ in wastewater copper factory and satisfactory results were obtained. The results are shown in Table 1.

Table 1. Determination of Cu in wastewater.

\begin{tabular}{llll}
\hline Sample & Added $(\boldsymbol{\mu g} / \mathbf{m L})$ & Found $^{\mathrm{a}}(\boldsymbol{\mu g} / \mathbf{m L})$ & Recovery\% \\
\hline \multirow{2}{*}{ No. 1} & 0.0 & $10.7 \pm 0.5$ & ---- \\
& 50.0 & $62.0 \pm 2.7$ & 102.6 \\
No. 2 & 0.0 & $18.3 \pm 0.8$ & --- \\
& 50.0 & $69.8 \pm 2.7$ & 103.0 \\
No. 3 & 0.0 & $29.7 \pm 1.1$ & --- \\
& 50.0 & $78.3 \pm 3.1$ & 97.2 \\
\hline
\end{tabular}

\begin{tabular}{llll}
\hline Sample & Added $(\boldsymbol{\mu g} / \mathbf{m L})$ & Found $^{\mathbf{a}}(\boldsymbol{\mu g} / \mathbf{m L})$ & Recovery $\%$ \\
\hline \multirow{2}{*}{ No. 4} & 0.0 & $83.1 \pm 2.9$ & --- \\
& 50.0 & $134.7 \pm 5.5$ & 103.2 \\
\hline
\end{tabular}

${ }^{\mathrm{a}}$ Average of three determinations \pm standard deviation.

\section{Conclusion}

This work has been demonstrated combination of DLLME with flame atomic absorption spectrometry provides a novel route for trace determination of $\mathrm{Cu}$ in wastewater samples. The main benefits of the DLLME methodology were: minimum use of toxic organic solvent, simplicity, low cost, enhancement of sensitivity, and rapid analysis time.

\section{References}

[1] F. Priego-capote, M. D. Luque de Castro, Trends Anal. Chem. 23 (2004) 644.

[2] V. Camel, Spectrochim. Acta Part B 58 (2003) 1177.

[3] M. Ma, F. F. Cantwell, Anal. Chem. 70 (1998) 3912.

[4] H. Prosen, L. Zupancic-Kralj, Tends Anal. Chem. 18 (1992) 272.

[5] S. Bjergaard, K. Rasmussen, T. Halvorsen, J. Chromatogr. A $902(2000) 91$.

[6] G. D. Christian, Anal. Sci. 15 (1999) 1033.

[7] A. Skoog, M. Donald, Fundamentals of Analytical Chemistry, 4th ed., Holt-Saunders International, 1982.

[8] M. F. Apendurada, J. Chromatogr. A 889 (2000) 3.

[9] N. Compillo, R. Penalver, I. Lopez-Garcia, M. Hernandez, J. Chromatography A, 1216 (2009) 6735.

[10] T. Chen, C. Breuil, S. Carriere, TAPPI J. 77 (1994) 235.

[11] P. D. Mc Donald, E. S. P. Milford "Solid Phase Extraction", Walters, Milford, MA, 6th ed., 1992, p. 287.

[12] W. L. Hinze, E. Pramauro, CRC Crit. Rev. Anal. Chem. 24 (1993) 133.

[13] D. M. Templeton, F. Ariese, R. Cornelis, L. G. Danielsson, H. Muntau, H. P. Van Leeuwen, R. Lobinski, Pure Appl. Chem. $72(2000) 1453$.

[14] T. Kumazawa, X. P. Lee, K. Sato, O. Suzuki, Anal. Chim. Acta 492 (2003) 49.

[15] H. Kataoka, H. Lord, J. Pawliszyn, J. Chormatogr. A 880 (2000) 35 .

[16] J. P. Hutchinson, L. Setkova, J. Pawliszyn, J. Chormatogr. A 1149 (2007) 127.

[17] A. Bidari, E. Zeini Jahromi, Y. Assadi, M. R. Milani Hosseini, Microch. J. 87 (2007) 6.

[18] P. Vinas, I. Lopez-Garcia, B. Merino-Merono, N. Campillo, M. Hernandez-C'ordoba, Anal Chim Acta 535 (2005) 49. 